\title{
COVID-19 y la neurosis de la arqueología en España: pasado, presente y futuro de la disciplina
}

\section{COVID-19 and the neurosis of archaeology in Spain: the discipline's past, present and future}

La pandemia de la COVID-19 ha supuesto una crisis sin precedentes en todo el mundo que ha activado el análisis y la reflexión sobre sus consecuencias en todos los ámbitos de la vida pública, económica y política, y que incluye a la disciplina arqueológica. Este texto tiene el objetivo de realizar un análisis del impacto de la pandemia sobre la disciplina en clave de larga duración, en tanto que la crisis de la COVID-19 vendría a agudizar un estado de crisis previa. Para ello, se defenderá que la arqueología en el Estado español sufría de una profunda situación de neurosis que generó distintos "elefantes en la habitación" que forman el campo de juego sobre el que la pandemia viene a impactar. Se defiende que esta situación de crisis también puede ser una oportunidad para analizar críticamente la propia ontología de la disciplina de forma que la salida de la crisis sanitaria no se convierta en una nueva forma de cambiar todo para que nada cambie.

Palabras clave: COVID-19, crisis, disciplina arqueológica, arqueología pública, gestión del patrimonio.
The COVID-19 pandemic is an unprecedented worldwide crisis that has triggered analyses and reflection on its effect on all spheres of public, economic and political life, including archaeology. This paper delves into the long-term impact of COVID-19 on the discipline as the pandemic has in fact exacerbated an earlier state of crisis. The argument is that archaeology in Spain has suffered from a deep neurosis that generated many different "elephants in the room" aggravating the effects of the pandemic. The paper likewise argues that this crisis can also serve as an opportunity to explore archaeology's ontology so that the path out of the health crisis not turn into a new way of changing everything to change nothing.

Keywords: COVID-19, crisis, archaeology, public archaeology, heritage management. 


\section{Introducción: COVID-19 o la lluvia sobre mojado ${ }^{1}$}

El 14 de marzo, después de unas semanas de incertidumbre, rumores y confusión, el Gobierno de España declara el Estado de Alarma en todo el territorio ante la expansión de la COVID-19, enfermedad provocada por el virus SARS-CoV-2. ${ }^{2}$ La declaración del Estado de Alarma no solo mostraba la gravedad de la situación, dado que había sido utilizada con anterioridad únicamente en una ocasión, ${ }^{3}$ sino que tuvo el efecto inmediato de paralizar toda la actividad económica del país. Para finales de marzo, todos los países de la órbita europea y de gran parte del mundo habían tomado medidas más o menos similares, transformando la crisis sanitaria en una irremisible crisis económica y, posiblemente y en algunos contextos, en una crisis política y social. Es en este escenario de desarrollo de la lucha contra la pandemia mundial y de la incertidumbre por el futuro que un importante número de voces surgieron para analizar el impacto de la COVID-19, unánimemente considerado como una ruptura estructural (VV.AA. 2020). En síntesis, tres serían los principales escenarios post-COVID que se plantean: en primer lugar, aquel que considera la pandemia como una oportunidad para re-pensar nuestras relaciones sociales y económicas en clave positiva, como sería la posición de autores como Yuval Noah Harari; ${ }^{4}$ en segundo lugar, un escenario más pesimista, que considera que las medidas de excepción tomadas por los distintos gobiernos pueden abrir la puerta a nuevas formas de control, de totalitarismo y/o de fortalecimiento de los nacionalismos excluyentes, entre los que se incluirían intelectuales como Byung-Chul Han $^{5}$ o Giorgio Agamben; ${ }^{6}$ y en tercer lugar, aquellas posiciones de corte más revolucionario que verían en la pandemia provocada por la COVID-19 como una vía para avanzar en una agenda social y superadora del capitalismo, como ocurriría con Slavoj Žižek (Žižek 2020) o, desde un punto de vista de género e identitario, Judith Butler. ${ }^{7}$

1. Agradecer a Juan Antonio Quirós, Alfonso Vigil-Escalera, Rafael Millán, Carlos Marín y Felipe Criado los comentarios sobre versiones iniciales de este texto. Un agradecimiento especial a Lois Armada por toda su ayuda para llevar a buen puerto este trabajo.

2. Real Decreto 463/2020, de 14 de marzo, por el que se declara el estado de alarma para la gestión de la situación de crisis sanitaria ocasionada por el COVID-19.

3. La otra declaración de Estado de Alarma se utilizó durante la conocida como "crisis de los controladores de 2010”, provocada por el cierre del espacio aéreo español por la convocatoria de huelga de los controladores aéreos de la empresa AENA.

4. <https://elpais.com/elpais/2020/04/06/planeta_futuro/1586170713_492779.html>.

5. <https://elpais.com/ideas/2020-03-21/la-emergencia-viral-yel-mundo-de-manana-byung-chul-han-el-filosofo-surcoreano-quepiensa-desde-berlin.html>.

6. <http://autonomies.org/2020/03/giorgio-agamben-the-coronaviris-and-the-state-of-exception/>.

7. <https:/ctxt.es/es/20200401/Politica/31943/Constanza-Michelson-entrevista-Judith-Butler-coronavirus-ideales-socialismo-democratico.html>.
Dentro de las posturas más críticas, y a pesar de las diferencias en el enfoque sobre el impacto concreto que tendrá la crisis, existen también algunos consensos. Uno de los consensos más relevantes es la idea de que la forma en la que se ha desarrollado el virus y el impacto que va a tener en términos geográficos y sociales está en estrecha relación con la configuración global y regional del capitalismo previo a la pandemia (Torres López 2020). En palabras de D. Harvey: "Public authorities and health care systems were almost everywhere caught shorthanded. Forty years of neoliberalism across North and South America and Europe had left the public totally exposed and ill-prepared to face a public health crisis of this sort" ${ }^{8}$ Del mismo modo, existe un cierto consenso en que el mundo que surgirá después de la pandemia no será exactamente igual al que había antes. En palabras de S. Žižek: "there is no return to normal, the new «normal» will have to be constructed on the ruins of our old lives, or we will find ourselves in a new barbarism whose signs are already clearly discernible" (Žižek 2020: 3). Dicho de otra manera, vivimos un estado de crisis, bajo los ecos y reverberaciones de la anterior crisis de 2008 (Mirowski 2014), que obligará a cada sector económico y a cada grupo y clase social a replantear su posición dentro del sistema. Una transformación que, en el caso de España, ha sido bautizada por el Gobierno como "nueva normalidad".

Así, y una vez pasada la etapa más mortífera de la pandemia, no fueron pocos los sectores y agentes sociales los que realizaron declaraciones y análisis en torno a los efectos de la pandemia así como sobre las propuestas para afrontar una situación calificada en más de una ocasión de "catastrófica". El sector de la arqueología, tanto en su vertiente más académica como más profesional/comercial, se unió también a este clima de incertidumbre. Así, a lo largo del mes de mayo, en plena fase de desescalada y de vuelta parcial a la actividad, se sucedió un significativo número de noticias sobre la situación del sector que ponían en la mesa del debate público el futuro de la disciplina (ver tabla 1).

Las notas comunes en estas noticias eran, por un lado, la paralización de las actividades comunes al sector - fundamentalmente, la gestión patrimonial y las excavaciones científicas-, y por otro, la situación de incertidumbre y desamparo en la que los distintos profesionales se encontraban. Muchas de ellas comentaban y difundían una encuesta realizada por la Plataforma Estatal de Profesionales de la Arqueología hecha pública el día 14 de mayo (Pepa 2020). Esta encuesta, realizada sobre 100 empresas y profesionales participantes (lo que representaría a un 3-5\% del total del sector, calculado entre 2500-3000 personas) presentaba los siguientes datos:

8. <https://www.jacobinmag.com/2020/04/david-harvey-coronavirus-pandemic-capital-economy $>$.

9. Concepto utilizado de forma masiva, según datos de Google Trends a partir del 25 de abril, primera declaración del Presidente del Gobierno que lo incorpora en sus discursos oficiales. 
Carlos Tejerizo-García, COVID-19 y la neurosis de la arqueología en España: pasado, presente y futuro de la disciplina

\begin{tabular}{|c|c|c|c|}
\hline FECHA & MEDIO & AUTOR & TITULAR \\
\hline $11-05-2020$ & La Razón & Javier Ors & Campañas arqueológicas en tiempos de coronavirus: ruina sobre ruinas \\
\hline $14-05-2020$ & El Español & D. B. / Agencias & $\begin{array}{l}\text { La ruina de la arqueología por el coronavirus: proyectos cancelados } \\
\text { y } 36 \text { millones de pérdidas }\end{array}$ \\
\hline $14-05-2020$ & Europapress & $\begin{array}{l}\text { Álex Zéa / Europa } \\
\text { Press }\end{array}$ & $\begin{array}{l}\text { El sector de la arqueología suma } 36 \text { millones de pérdidas y más de } \\
\text { la mitad de los profesionales "parados" }\end{array}$ \\
\hline $14-05-2020$ & El Heraldo & Mariano García & $\begin{array}{l}\text { Las excavaciones arqueológicas de verano, reducidas casi a la nada } \\
\text { por el coronavirus }\end{array}$ \\
\hline $14-05-2020$ & Redhistoria & $\begin{array}{l}\text { Marcelo Ferrando } \\
\text { Castro }\end{array}$ & $\begin{array}{l}\text { El } 55 \% \text { de los arqueólogos están sin trabajo y las pérdidas del sector } \\
\text { superan los } 36 \text { millones }\end{array}$ \\
\hline $15-05-2020$ & Infoenpunto & Redacción & $\begin{array}{l}\text { La mitad de los arqueólogos están en paro y las pérdidas del sector } \\
\text { superan los } 36 \text { millones de euros }\end{array}$ \\
\hline $15-05-2020$ & El País & Peio H. Riaño & La arqueología se queda sin empleo, ayudas ni futuro \\
\hline $19-05-2020$ & El País & Peio H. Riaño & El patrimonio reclama ayudas específicas al ministro de Cultura \\
\hline $22-05-2020$ & El Mundo & Francisco Carrión & $\begin{array}{l}\text { El coronavirus golpea a la arqueología española: } 36 \text { millones de pér- } \\
\text { didas y el } 55 \% \text { de los profesionales en paro }\end{array}$ \\
\hline $24-05-2020$ & Diario Sur & Iker Cortés & $\begin{array}{l}\text { Carlos Caballero: "La arqueología da vida a la España vacía y pone } \\
\text { en marcha sus recursos turísticos" }\end{array}$ \\
\hline $30-05-2020$ & La Opinión de Murcia & Héctor Uroz Rodríguez & Arqueólogos en crisis \\
\hline $30-05-2020$ & La Vanguardia & María Ruiz & La arqueología, una mirada al pasado para blindar el futuro \\
\hline
\end{tabular}

Tabla 1. Tabla con las principales noticias sobre arqueología en mayo de 2020.

- $55 \%$ del sector afirma que su actividad se ha paralizado por completo durante el Estado de Alarma.

$-45 \%$ de encuestados espera retrasos en los pagos comprometidos, mientras que un $10 \%$ da por perdidas ayudas o subvenciones con las que contaba para el ejercicio profesional durante el año 2020.

- A partir de 75 respuestas para la pregunta: "Cuantifica la repercusión económica”, se calculó que el impacto total acumulado es 1,1 millones de euros. 14,581,68 euros por participante. Esto llevaba a plantear un impacto global de 36 millones de euros.

En el mismo informe, la Plataforma planteaba distintas medidas para frenar el impacto económico de la pandemia sobre el sector, que incluía cuestiones como el aplazamiento o condonación de las deudas de las empresas o las personas autónomas, la condonación de deudas con la administración, la reducción del IVA cultural o implementar bonificaciones fiscales (Pepa 2020: 9). En el fondo, medidas destinadas a un tipo de sector muy extendido en la economía española desde los años noventa, caracterizado por la precarización y basado en la presencia de PYMES y autónomos (Lacalle 2006). A mayores, el mismo informe presentaba medidas más estructurales y de largo alcance, que incluía la revisión de las leyes de Patrimonio Cultural, la dotación de prestigio profesional y seguridad a la profesión, la implementación de convenios propios o la creación de un Plan de Sostenibilidad del Patrimonio Cultural en el mundo rural (Pepa 2020: 10). Medidas que, por otro lado, han sido reivindicaciones comunes del sector en los años previos a la actual crisis (Almansa Sánchez 2013).

Este informe se complementó el día 19 de mayo de 2020 con el envío de una carta al titular del Ministerio de Cultura y Deporte, José Manuel Rodríguez Uribes, en el que se le instaba a incluir medidas específicas para el sector de la arqueología. Tanto la Plataforma como el Colegio de Arqueólogos de Madrid —que forma parte de la Plataforma- denunciaban que en el Real Decreto para la toma de medidas excepcionales que el Gobierno había tomado en el sector de la Cultura, ${ }^{10}$ la arqueología y el patrimonio habían quedado abandonados. Una velada declaración de intenciones que amenazaba con ser una posición estructural de cara al futuro del patrimonio.

Teniendo en cuenta estos antecedentes, no hay duda de que la crisis derivada de la COVID-19 tendrá un gran impacto en la arqueología de España. Igualmente, no cabe duda de que surgirán, por necesidad y obligación, numerosos análisis sobre cómo afrontar el futuro de la disciplina. La arqueología post-COVID está llamada a ser tema de reflexiones, artículos (que, dependiendo del firmante, tendrán mayor o menor impacto académico y mayor o menor influencia), conferencias y mesas de congresos. Este texto debe entenderse entonces como un texto de urgencia; uno más de entre los muchos que habrá sobre este tema - y escrito desde la posición de un investigador postdoctoral de la arqueología actualmente con un contrato de seis meses-, y pretende ser una pieza más del enorme puzle que será este debate. Un debate que tiene que darse cuanto antes porque del mismo modo que la pandemia se extendió a velocidades inusitadas, su impacto también tendrá dimensiones

10. Real Decreto-Ley $17 / 2020$, de 5 de mayo, por el que se aprueban medidas de apoyo al sector cultural y de carácter tributario para hacer frente al impacto económico y social del COVID-2019. 
enormes en tiempos muy reducidos (Torres López 2020). Cuanto antes se inicie, antes se pondrán las reflexiones al servicio de las personas interesadas $\mathrm{y}$, en su caso, soluciones a la previsible situación de incertidumbre en torno al lugar del patrimonio y de la arqueología en España.

En el texto que sigue se defenderán las siguientes posiciones. En primer lugar, que la actual situación de crisis en la disciplina arqueológica se construye sobre un modelo que ya estaba en crisis (Hernando 2012b). Una crisis con una larga genealogía cuyas bases se relacionan, en el caso español, con su institucionalización tanto en la academia como en la construcción de la llamada arqueología comercial a partir de la promulgación de la Ley de Patrimonio Histórico de 1985. Dos vertientes, la académica y la comercial, que tuvieron tanto en la implantación del Plan Bolonia como en la crisis financiera de 2008 dos soluciones de continuidad de los que estábamos, en tanto que sector, adaptándonos y recuperándonos. Ambas, por su parte, se construyen sobre un entramado estructural de la arqueología cuya génesis hay que rastrear, en primer término, en la constitución de la disciplina a finales del siglo XIX y principios del siglo xx (Díaz-Andreu 2002) y, en segundo término, en los procesos de constitución del campo científico de la arqueología durante el Franquismo y los momentos inmediatos a la muerte del dictador (González-Ruibal 2012a; Gracia Alonso 2009). En este sentido, lo que se defiende es que la actual crisis supone, en gran medida, una lluvia sobre mojado, por lo que es necesario analizar el estado en el que se encontraba la arqueología para poder afrontar su futuro y evitar así la peligrosa paradoja lampedusiana de "cambiar todo para que nada cambie".

En segundo lugar, se defenderá que esta crisis que ya gravitaba sobre la disciplina se articula en torno a cuatro "elefantes en la habitación", esto es, grandes problemas y contradicciones de la arqueología española que, aunque presentes y visibles, será necesario dejar de ignorar para afrontar un incierto futuro. Estos elefantes serían: la arqueología comercial, la formación arqueológica, la situación de la academia, y la arqueología pública. Comprender los problemas estructurales que ya estaban presentes en la disciplina es clave para determinar su papel en la "nueva normalidad" y si se repetirán viejos errores o se puede afrontar una verdadera transformación en clave positiva de la arqueología en tanto que disciplina social; si la historia se repetirá como farsa o como tragedia (Žižek 2016).

En este sentido, y en tercer lugar, lo que se defenderá es que, lejos de posiciones victimistas y exculpatorias, hay que confrontar la realidad de que la situación de crisis permanente y del impacto que tiene y tendrá la crisis del COVID-19 es, en gran medida, nuestra responsabilidad como colectivo, cada uno desde su parcela de actuación. Del mismo modo, esto implica una toma de responsabilidad también para las soluciones; dicho de otra manera, convertirnos en agentes activos tanto en las causas como en las soluciones (Chomsky 1969). En cierta medida, y en mi opinión, estos elefantes en la habitación son el resultado de lo que podemos denominar una "neurosis" consustancial a la disciplina arqueológica y que forma parte, en términos generales, de las relaciones económicas capitalistas en las que la arqueología se inserta (Jessop 2016; Marcuse 2010). La neurosis se define como un trastorno psicológico que, sin producir una disociación con la realidad -lo que la diferencia de la psicosis-, genera situaciones de angustia o ansiedad que provocan una estrategia de "huida hacia adelante" como vía de escape. Así, desde una lectura a partir de Freud y Lacan: "es en este momento cuando Freud plantea que en la neurosis se evita la realidad, en una huida, un escaparse de la percepción de un trozo de la realidad. La neurosis no niega la realidad, "se limita a no querer saber nada de ella", destaca Freud, y en el intento de sustituir el fragmento de la realidad indeseado por otro apela al recurso de la fantasía, que le provee elementos del pasado, cuando la realidad era más satisfactoria" (Napolitano 2013: 50). Y es esta relación contradictoria con la realidad y la huida hacia adelante la que, defiendo, ha caracterizado a la arqueología en los últimos cuarenta años y que ha conformado el gigante con pies de barro previo que la COVID-19 ha venido a derribar.

Siguiendo esta lógica, el texto analizará primero por separado cada uno de esos "elefantes en la habitación”, para luego reflexionar sobre una arqueología post-COVID en la que, por un lado, se propongan, al menos potencialmente, algunos cimientos para superar esas contradicciones $\mathrm{y}$, por otro, se avance en una agenda que haga de la arqueología una ciencia socialmente útil, un barco en el que, considero, estamos todas las personas involucradas, sea por retórica o por convicción. En su clásico estudio sobre la Doctrina del shock, la periodista canadiense Naomi Klein advertía sobre los marcos que la situaciones de crisis generaban y que podían ser aprovechados para la imposición de agendas neoliberales y/o autoritarias (Klein 2008). Esta lectura tiene un doble sentido, en tanto que advertencia de lo que puede ocurrir (precarización del sector, destrucción del patrimonio, pérdida de significancia social...), pero también de oportunidad para avanzar en otras direcciones, esto es, en convertir las crisis en espacios de transformación en clave progresista y emancipadora. Espero que las reflexiones que siguen ayuden a alejarnos del primer escenario y a construir el segundo.

\section{La arqueología comercial: la crisis como vieja normalidad}

Si hay un sector dentro de la disciplina arqueológica que ha sido "neurótico", este ha sido el de la arqueología comercial (sensu Parga-Dans et al. 2012). Una neurosis que está estrechamente relacionada con el contexto de su génesis. Su emergencia en cuanto sector, tras la promulgación de la Ley de Patrimonio Histórico de 1985, se desarrolló en un marco de fuerte implementación de las políticas neoliberales en España durante los años noventa - la Ley del Suelo, que vino a legislar un proceso plenamente activo de liberalización de este bien, es de 1998-, que marcó irremediablemente las características fundamentales del sector: nicho fundamentado en tareas de bajo 
valor añadido - fundamentalmente, aunque no de forma exclusiva, la liberalización del suelo para la construcción-, mercado extremadamente desregulado que abocó a una fuerte competitividad y a la consiguiente precarización del trabajo, y bajos niveles de márgenes de beneficios que forjaron un sector tremendamente inestable (Marín Suárez y Parga-Dans 2015; Parga-Dans 2009). A esto habría que sumar, como un componente determinante para el sector, la preeminencia de las Comunidades Autónomas en tanto decisoras y gestoras de las competencias en cuestiones de Patrimonio, lo que generó marcos de actuación y de clientelismo muy determinados (Ruiz Zapatero 2016).

De esta forma, se creó un sector con un componente de clase muy particular en el que priman las pequeñas empresas y los autónomos -en muchas ocasiones en la forma de "falso autónomo"- que generaron una escasa conciencia sectorial y organización sindical (Díaz del Río 2000). ${ }^{11}$ La negociación de los convenios colectivos a lo largo de la primera década del siglo en Comunidades Autónomas como Madrid, Cataluña, Galicia o Castilla y León puede considerarse el mayor éxito colectivo del sector, si bien con límites y no exento de críticas (Almansa Sánchez 2013; Vigil-Escalera 2011). Sin embargo, tras estos momentos de agudización de la lucha colectiva, se volvió de nuevo a una situación reactiva, en la que los escasos Colegios de Profesionales que se formaron en el período fueron el vector fundamental de articulación de la defensa del sector aunque también, en ocasiones, de intereses particularistas y clientelares.

Si bien el sector estaba mayoritariamente enfocado a la liberalización del suelo, también hubo una tendencia a la diversificación de sus actividades: creación de museos, turismo patrimonial o actividades divulgativas fueron algunas de las actividades y nichos que se fueron abriendo en estos años, dentro de una lógica neoliberal del multi-tasking arqueológico ${ }^{12}$ (Querol 2010). Sin embargo, muchas de estas actividades eran fuertemente dependientes de una inversión pública, en muchas ocasiones voluntaria y circunstancial más que estructural y estabilizada. Así, los proyectos de intervención se llenaron de propuestas que, basadas en una supuesta promoción del patrimonio territorial, acabaron por fagocitar importantes cantidades de dinero y recursos cuya gestión y resultados fueron más que cuestionables (Alonso González 2017). Las políticas a corto plazo y la falta de planificación e instrumentalismo del patrimonio terminaron en muchos casos en yacimientos abandonados, centros de interpretación vacíos y carteles señalizadores sin poner (Ayán Vila y Gago 2012). Un aspecto sobre el que luego retornaré en tanto que materialización de las relaciones que se establecen con las comunidades locales.

Centrándonos específicamente en la arqueología comercial, su configuración en estos términos provocó

11. Sin duda, con excepciones, como fueron la asociación AMTTA en Madrid o la sección sindical de la CNT en Barcelona (Marín Suárez y Parga-Dans 2015). Pero, sin duda también, fueron más excepciones que reglas comunes.

12. Esta reflexión se la debo a Rafael Millán. que la crisis del 2008 impactara de forma tremendamente agresiva sobre el sector (Novakovic et al. 2016; Parga-Dans 2010). La falta de una regulación sólida, de una administración que defendiera el patrimonio frente a los recortes y de un tejido colectivo fuerte generó los efectos característicos de las crisis capitalistas (Houben 2012): destrucción de los medios de producción (pequeñas empresas y autónomos), concentración del capital en unas pocas empresas beneficiadas por la situación, disminución de los costes de producción y precarización generalizada del trabajo, asumida fundamentalmente por los trabajadores y trabajadoras a través de la reducción de salarios, empeoramiento de las condiciones de trabajo o la sobreexplotación (González Álvarez 2013).

La lenta recuperación de la crisis a través de la aplicación de recetas fundamentalmente neoliberales permitió, con el tiempo, ir recuperando parte de los niveles de producción del sector previos a la crisis. Esto se consiguió principalmente gracias a la conjunción de tres factores: un aumento progresivo y muy tibio de la inversión pública en el sector de la construcción y en actividades vinculadas al patrimonio; el mantenimiento y la asunción de grandes cuotas de precariedad provenientes del período postcrisis; y la expansión del sector a través de la diversificación de actividades. Al no existir una regulación específica del sector y de los mercados asociados, se generaron fuertes espacios de competitividad que ocasionaron no pocos conflictos de gran calado y que, de nuevo, mostraban un sector poco cohesionado y con pocos instrumentos de acción colectiva (Marín Suárez y Parga-Dans 2015). Sin duda, la situación general de la arqueología comercial ha mejorado desde la crisis de 2008 -dependiendo de las regiones y, también, a un alto coste en términos de precarización y de calidad del trabajo-, pero en un estado de latencia y de tensión interna que amenazaba con estallar ante la mínima coyuntura negativa.

Este es el patio mojado sobre el que ha caído la lluvia de la crisis del COVID-19. La paralización de la actividad económica en marzo de 2020 y su lenta desescalada en los meses siguientes han generado un estado de incertidumbre y pánico. Como afirma Carlos Caballero, coordinador de la Plataforma Estatal de Profesionales de la Arqueología, comparando la situación con 2008:

No sé si es peor o no porque la situación es un poco imprevisible. La de entonces era una crisis económica a escala mundial en la que todos íbamos en el mismo barco y más o menos se podía prever la reacción de las administraciones públicas... Depende, en todo caso, de las administraciones públicas y de cómo el inversor privado perciba la situación. Ahora mismo la perspectiva es mala. Quizá a medio plazo no sea tan mala. ${ }^{13}$

De alguna manera, lo que se pone en el centro de la cuestión, y sobre lo que luego volveremos, es la centralidad de la futura actitud y voluntad tanto de la administración pública como de la inversión privada en la recuperación del sector, desviando de alguna

13. <https://www.diariosur.es/culturas/carlos-caballero-arqueologia-20200524184140-ntrc.html>. 
manera la responsabilidad hacia agentes externos al propio colectivo. Sin embargo, y dadas las características del sector y sus problemáticas estructurales, este tipo de estrategias podría acabar siendo como poner un poco de cemento a una presa desbordada.

Un estado de incertidumbre en el que la encuesta de la Plataforma que comentábamos al principio venía a mostrar una preocupación generalizada del sector que solo ha podido ser canalizada a través de los pocos instrumentos colectivos que quedaron de la anterior crisis. Los efectos inmediatos de la pandemia de la COVID-19 ya se han hecho notar, como demuestran los (todavía parciales) datos de la citada encuesta: cancelación de trabajos, pérdidas de ingresos y endeudamiento o amenaza de cierres de empresas y salida de autónomos. Sin embargo, todo parece indicar que lo peor está por llegar. El escenario más probable es que la inversión pública en áreas relacionadas con el patrimonio sea uno de los primeros sectores en ser recortados en el futuro inmediato - es significativo, como bien expresó el Colegio de Arqueólogos de Madrid, que, en el Real Decreto de medidas para el sector de la Cultura, el Patrimonio quedará fuera de los sectores mencionados-; por otro lado, es posible que una de las vías de salida de la crisis sea la profundización en la desregulación de ciertos sectores como el de la construcción, que impliquen (incluso) menos controles arqueológicos y patrimoniales, con la consiguiente pérdida tanto en términos de trabajo para el sector como en términos históricos y patrimoniales (destrucción de yacimientos, pérdida de identidad histórica, etc.). Estas medidas no se han hecho esperar. Como parte de la doctrina del shock, la Comunidad de Madrid publicó un Anteproyecto de Ley del Suelo que, según las alegaciones interpuestas el 30 de mayo por el Colegio de Arqueólogos de Madrid, amenaza seriamente con desproteger el Patrimonio de la región. ${ }^{14}$ Una nueva normalidad que podría recordar, si no se implementan soluciones alternativas, a la vieja normalidad de la arqueología comercial.

\section{La formación arqueológica: Bolonia y los deberes sin hacer}

La institucionalización de la formación arqueológica en España tiene un largo recorrido que se inicia con la propia constitución de las universidades como centros de la enseñanza superior (Hernández Díaz 1997; Hernando Álvarez y Tejerizo García 2011). Hasta muy recientemente, esta formación se insertaba, mayoritariamente, dentro de los planes de estudio de historia, bajo el paradigma de que la arqueología era una ciencia auxiliar de la historia (Querol 1998, 2005). Sin embargo, la promulgación de la Ley de Patrimonio Histórico y el desarrollo de la arqueología comercial pronto pusieron de relieve las contradicciones de este paradigma y la necesidad de generar una formación específica para los y las futuras profesionales de la

14. <https://www.arqueologiademadrid-cdl.org/alegaciones-al-anteproyecto-de-la-ley-del-suelo-de-la-comunidad-de-madrid/? fbclid=IwAR1Ue0IEg71OH2pDxrCXPTkshty_ ksf876-aymSmKOjRXS_s11XFmC9Pgko>. disciplina (Querol 2001; Ruiz Zapatero 2005, 2009). La ocasión se presentó con la reforma conocida como "Plan Bolonia", que adaptaba la universidad española al Espacio Europeo de Educación Superior (EEES). Una reforma que articuló un importante movimiento en contra y diversas críticas en su momento por su carácter elitista y de orientación privatizadora (Alegre y Moreno 2009; Capella 2009; Fernández Liria y Serrano García 2009; Serrano García 2009). En opinión de Carlos Fernández Liria, "los estudiantes anti-Bolonia, que lucharon durante diez años en las calles para defender su Universidad, tenían, como se ha demostrado, toda la razón"..$^{15}$ Paradójicamente, y a pesar de todas estas críticas y protestas, en el caso de la arqueología se posibilitó la creación de los primeros títulos específicos para la disciplina (Hernando Álvarez y Tejerizo García 2011).

El Plan Bolonia estructuró la enseñanza superior a partir de tres grandes ciclos: el grado, el máster y el doctorado. En relación con los planes de estudios anteriores, se establecía una mayor carga de profesionalización sobre el máster (uno-dos años) frente al grado (cuatro años), más largo pero menos denso en contenidos. Esta decisión tuvo varias implicaciones, entre las que cabe destacar la simplificación de las competencias y de las materias, el mayor peso del máster sobre el grado y, por consiguiente, el aumento de la presión financiera sobre el alumnado.

Así, los grados de Arqueología han sido una significativa novedad del Plan Bolonia, siendo pionero el Grado de Arqueología implantado por la Universidad Complutense de Madrid en el curso 2010/2011. En la actualidad, se imparte Grado en Arqueología en las universidades de Granada, Sevilla y Jaén, funcionando como grado conjunto (implementado en 2013/2014), la Universidad Autónoma de Barcelona, la Universidad de Barcelona y la Universidad Rovira i Virgili, además de universidades como la de Navarra, que los imparten como parte de sus titulaciones propias. En un análisis publicado hace ya algunos años, pero que no se ha visto modificado en sus líneas principales (Hernando Álvarez y Tejerizo García 2011: 60-63), se caracterizaban estos grados de arqueología bajo ciertos parámetros comunes. En primer lugar, una vinculación muy estrecha con las materias relacionadas con la historia, que copan gran parte de los planes de estudio. En segundo lugar, una escasa carga de asignaturas puramente metodológico-prácticas, y en tercer lugar, una escasa atención al desarrollo de asignaturas de corte teórico, que se trasladan al máster como ámbito de la profesionalización real en arqueología. A pesar de ello, se planteaba un escenario muy positivo en cuanto al desarrollo de una disciplina, la arqueología, cuyo papel en las sociedades actuales ha sufrido un cambio radical en los últimos veinte años, ampliando sus horizontes de posibilidad hacia distintos ámbitos de la arqueología pública (Almansa Sánchez 2013; Barreiro Martínez 2013; Moshenska 2017; Ruiz Zapatero 2016). Sin embargo, la arqueología como formación se insertó fundamentalmente en el ciclo

15. <https://www.cuartopoder.es/ideas/2020/05/15/la-universidad-vaciada-carlos-fernandez-liria/>. 
superior del máster. Esto se debió a varios factores, entre los que destacan la convergencia de una escasa o nula inversión en la contratación de nuevo personal laboral junto a las facilidades administrativas que suponía crear un máster frente a un nuevo grado, fundamentalmente reciclando y adaptando viejos planes de estudio al nuevo marco normativo (Ruiz Zapatero 2016: 65). Las formas en las que la arqueología se conceptualizó e implementó en los distintos másteres en la península ibérica han sido muy variadas y con un desarrollo desigual, lo que ha generado no pocas contradicciones en su desarrollo práctico (Hernando Álvarez y Tejerizo García 2011; Ruiz Zapatero 2016). Aunque aún faltan análisis específicos sobre este tema, una de las contradicciones más importantes es, sin duda, la descompensación entre los niveles y coste de la formación, el número de especialistas formados y la limitación de un mercado laboral que no es capaz de absorber toda esta masa de personas graduadas, maestras y doctoradas (Parga-Dans 2009; Ruiz Zapatero 2016).

Dentro de esta formación arqueológica, un aspecto que ha sido crucial, a la par que problemático, ha sido la cuestión de las prácticas. La ausencia de una estructura formal y regulada para la ejecución de estas prácticas generó un pantanoso agujero negro en el que, en el mejor de los casos, se ofertaba desde las universidades posibilidades de prácticas arqueológicas que normalmente implicaban horas no lectivas del alumnado y, en el peor de los casos, situaciones de explotación laboral encubierta y uso de mano de obra barata (por no decir directamente esclava) para proyectos de investigación o actuaciones de urgencia en marcha; una formación "a golpe de talonario" en la que no solo se descargaba en el alumnado todos los costes suplementarios de su formación sino que se extraía su fuerza de trabajo en condiciones extremadamente precarias (Tejerizo García y Hernando Álvarez 2012). Como argumenta D. González, estas excavaciones de verano generan, tendencialmente, "superarqueólogos" (en masculino) que asumían ciertas prácticas y relaciones que les preparaban para la futura precarización en el mercado laboral (González Álvarez 2013).

La formación arqueológica ha supuesto un buen ejemplo de esa estrategia de resiliencia, en el sentido negativo del término (Derickson 2016), y de huida hacia adelante que caracteriza a la neurosis de la disciplina que la COVID-19 amenaza con profundizar. La situación de confinamiento en pleno curso lectivo ha provocado auténticas situaciones de caos y de adaptación ad hoc que amenazan, en términos de doctrina del shock, con quedarse para siempre (Klein 2008). Las declaraciones del ministro de Universidades, el sociólogo Manuel Castells, que aboga por un acercamiento de las universidades españolas hacia el paradigma anglosajón en términos de digitalización de la enseñanza y la implementación de sistemas online ${ }^{16}$ ya han generado respuestas en términos de liberalización y privatización de la enseñanza superior. Así, el presidente de la Xunta de Galicia, Alberto Núñez Feijóo, recogió este guante dejado por el ministro y presentó el 25 de mayo de 2020 una propuesta que implicaba la introducción de entidades privadas en espacios de gestión y consultoría a las universidades públicas, bajo la idea de implementar la educación online. ${ }^{17}$ Propuesta que, unos días después, sería retirada, pero que señala un potencial camino hacia una reestructuración en clave privatizadora de la enseñanza universitaria. En términos de formación arqueológica, este camino podría derivar no solo en la profundización de los anteriores problemas comentados, sino también en una pérdida de terreno en cuestiones claves como son las prácticas arqueológicas que deriven en un empeoramiento de la formación y una sobreexplotación del alumnado.

\section{Academia y arqueología: entre la omertá y el publish or perish}

Durante los años 2018 y 2019 me presenté a un total de tres plazas de ayudante doctor en distintas universidades del Estado español. Todas estas plazas conllevaban un número muy alto de tareas y horas de dedicación tanto a docencia como a investigación con una retribución que se acercaba, en el mejor de los casos, al mileurismo. En todos esos procesos ya se sabía que existía un candidato o candidata "de la casa" que, en los tres casos, resultaron ser las personas elegidas para el puesto. Para que quede claro, en ninguno de estos casos creo que yo fuera el mejor candidato, pero sí que, en términos exclusivamente curriculares, en algunos de estos procesos había mejores candidatos que las personas que resultaron elegidas. Nadie inició reclamaciones administrativas y estos puestos quedaron finalmente ocupados por los candidatos y candidatas "(extra)oficiales".

Este relato es un lugar común bien conocido por todas aquellas personas que se encuentran dentro de la academia española en general y en la arqueológica en particular, una disciplina en la que, incluso en los mejores tiempos, no abundan las plazas de concurso público. Un relato que demuestra dos importantes problemas estructurales de la disciplina arqueológica (compartidos, por otro lado, con la universidad en general): por un lado, la precarización de los puestos de trabajo en la academia (ver figura 1) y, por otro, la endogámica y extendida red de clientelismo y nepotismo. La precarización de la universidad española es un proceso de larga duración que se ha ido tensionando y agudizando con cada nueva reforma de las leyes universitarias (Castillo y Moré 2018). En esencia, esta precarización se ha materializado a través de tres vías complementarias. En primer lugar, en el uso cada vez más extendido de las figuras administrativas más precarizadas para cubrir puestos que, originalmente, estaban pensados para otras más estables o mejor remuneradas, como por ejemplo, utilizar la figura de profesor ayudante 


\begin{tabular}{|c|c|c|c|c|c|}
\hline & PDI Total & $\%$ Mujeres & $\begin{array}{l}\text { PDI (en } \\
\text { ETC) }\end{array}$ & $\begin{array}{c}\begin{array}{c}\text { Tasa de } \\
\text { variación } \\
\text { anual }\end{array} \\
\end{array}$ & \\
\hline Total SUE & 120.383 & 41,3 & $82.469,0$ & 1,9 & \\
\hline Univ. públicas & 102.297 & 40,8 & $72.841,2$ & 1,3 & \\
\hline Univ.públicas. Centros propios & 96.859 & 40,5 & $70.275,5$ & 1,3 & \\
\hline Funcionarios & 43.318 & 35,7 & $42.701,1$ & $-2,4$ & Distribución de los funcionarios \\
\hline Catedráticos de Universidad (CU) & 10.017 & 21,3 & 9.882 .2 & 1,9 & $23,1 \%$ \\
\hline Titulares de Universidad (TU) & 28.057 & 40,3 & $27.656,5$ & $-2,9$ & $64,8 \%$ \\
\hline Catedráticos de Escuela Universitaria (CEU) & 861 & 31,0 & 854.4 & $-8,8$ & $2,0 \%$ \\
\hline Titulares de Escuela Universitaria (TEU) & 4.284 & 40,2 & 4.209 .1 & $-7,4$ & $9,8 \%$ \\
\hline Otro persongl funciongrio & 99 & 38,4 & 98.8 & -8.3 & $0.2 \%$ \\
\hline Contratados & 52.847 & 44,7 & $27.233,2$ & 4,6 & Distribución de los contratados \\
\hline Ayudante & 575 & 48,7 & 574,2 & -19.4 & $1,1 \%$ \\
\hline Ayudante Doctor & 3.223 & 50,4 & $3.223,0$ & 1,5 & $6.1 \%$ \\
\hline Contratado Doctor & 11.347 & 48,6 & 11.300 .4 & 9.0 & $21.5 \%$ \\
\hline Asocigdo & 22.871 & 40.3 & 5.618 .3 & 6.0 & $43.3 \%$ \\
\hline Asocigdo C.C.Salud & 8.679 & 45.0 & 1.355 .3 & 2.1 & $16.4 \%$ \\
\hline Colaborador & 2.028 & 46.3 & 2.015 .7 & -6.6 & $3.8 \%$ \\
\hline Visitante & 903 & 45.5 & 805,8 & 7.6 & $1,7 \%$ \\
\hline Otros & 3.223 & 52,8 & 2.340 .4 & 2,8 & $6.1 \%$ \\
\hline Eméritos & 694 & 25,8 & 341,2 & 1,5 & \\
\hline Univ.públicas. Centros adscritos & 5.438 & 45,1 & $2.565,6$ & 0,4 & \\
\hline Univ. privadas & 18.086 & 44,0 & $9.627,9$ & 5,9 & \\
\hline Univ. privgdas. Centros propios & 16.927 & 44,4 & 9.220 .3 & 6.3 & \\
\hline Univ. privgdas. Centros adscritos & 1.159 & 38.7 & 407.6 & 1.4 & \\
\hline
\end{tabular}

Figura 1. Personal docente e investigador en el curso 2016-2017. Extraído de Ministerio de Ciencia 2019. Destacar aquí el dato sobre la tasa de variación anual de cada categoría.

doctor para responsabilidades correspondientes a un profesor contratado doctor, o esta última para cubrir plazas que deberían ser cubiertas por un puesto fijo de profesor o investigador titular. En segundo lugar, el uso extendido de las becas y los contratos temporales como estrategia para evitar los costes añadidos de la estabilización de la plantilla universitaria sumado a una sobreexplotación de las personas que asumen estas becas y contratos, asunto que las distintas asociaciones de becarios han denunciado con insistencia desde la crisis de 2008. ${ }^{18}$ En tercer lugar, el uso de una vía de reducción progresiva de los derechos laborales y académicos, así como de las retribuciones de los sectores más precarizados. De alguna manera, esta precarización se ha ido asumiendo por una conjunción de la pasividad del funcionariado ya permanente junto con una autoexplotación de los sectores más precarizados en aras de "meter la cabeza en la

18. Para este tema, se recomiendan los distintos foros de precarios.org. universidad esperando una plaza decente" (Castillo y Moré 2018: 91 y ss.).

Junto a esta precarización, el nepotismo y clientelismo de la universidad española es un aspecto conocido y asumido pero que no ha sido analizado de forma sistemática. Una omertá o secreto a voces del que se participa colectivamente en mayor o menor medida, por acción o por omisión. Víctor Sampedro, catedrático de Opinión Pública de la Universidad Rey Juan Carlos, lo expresaba con las siguientes palabras al denunciar este problema estructural de la universidad española:

Yo puedo dar mi nombre porque me lo he ganado, ya soy catedrático, pero entiendo que todos los demás que aún no son titulares no quieran figurar, porque cualquier denuncia pública supondría la exclusión automática de la carrera de ascensos. Las represalias están a la orden del día. ${ }^{19}$

19. <https://www.elconfidencial.com/alma-corazon-vida/2018-03-08/educacion-enchufes-universidad-profesores_1530998/>. 
La razón para esta omertá disciplinaria tiene que ver con un sistema de recompensas y represalias instituidas en tanto que habitus dentro del campo de juego asumido por la universidad y el campo de la investigación (Bourdieu 2003; Latour y Woolgar 1986). En Homo Academicus, P. Bourdieu analizaba cómo en la creación del campo universitario se establecían unas reglas de juego que generaban una escala de beneficios y perjuicios en función de la posición que se ocupe dentro del campo científico. Así, aquellos que están en el centro de acumulación del capital científico tienen una mayor capacidad para establecer las reglas que permitían el mantenimiento y la reproducción del sistema. En este campo de relaciones se estructuran los mecanismos de reproducción que se alimentan del mantenimiento de una cierta ortodoxia o, lo que es lo mismo, del rechazo y expulsión de la heterodoxia - que no equivale necesariamente a transformadora, sino a alternativa a la ortodoxia. Mecanismos que, a la larga, se convierten en aspectos estructurados y estructurantes del propio sistema (Bourdieu 1984). La consecuencia lógica es que los mecanismos de introducción del nuevo personal al campo científico se convierten en un campo de batalla entre la reproducción del sistema mediante la incorporación de personas afines al establishment y el rechazo a aquellas que no forman parte de unas relaciones clientelares específicas.

Analizar esto con cierta rigurosidad en la actual academia española en general y en la arqueológica en particular, más allá de declaraciones puntuales o los rumores de pasillo - los que no dejan de ser un elemento de resistencia y contestación en sí mismo, si bien desarticulados y con escasa incidencia en el sistema (Scott 1985) — es, por el momento, impensable. Hasta recientemente, la aceptación tácita de esta regla del campo de juego se asumía con un cierto grado de cinismo así como por una cierta predicación del principio del "café para todos". De alguna manera, en los períodos de bonanza económica y de aumento de la inversión tanto de las administraciones centrales como autonómicas -estas últimas con un papel muy importante en la promoción de universidades regionales dentro de particulares estrategias políticas- los distintos agentes podían asumir este grado de nepotismo en cuanto que había una demanda de trabajo suficiente para cubrir la mayor parte de la oferta de trabajadores. Dicho de otra manera, en los momentos expansivos de entrada de titulares a las universidades se permitía des-tensionar las redes de clientelismo y el nepotismo (González-Ruibal 2012b). En el momento en el que se produce una contracción de la inversión pública y de la oferta de plazas, como ocurrió a lo largo de la primera década del nuevo siglo y tras la crisis de 2008 , se produjo un efecto "embudo" en el que las redes de clientelismo y patronazgo fueron, y son, uno de los mecanismos principales de entrada en la universidad (Bourdieu 1984), lo que ha generado numerosos conflictos, denuncias y, todo hay que decirlo, muchas injusticias manifiestas, canalizadas en ocasiones por vía administrativa e, incluso, judicial. En este contexto, y si no se afronta este elefante en la habitación de forma seria y directa, no sería muy extraño que el escenario
post-COVID profundice estas redes clientelares que benefician a algunos y perjudican a otros $-\mathrm{y}$ muy posiblemente y con mayor incidencia, a otras, en femenino (Sánchez Romero 2005) - como consecuencia de una contracción de la demanda causada por los recortes en inversión pública.

La otra pata de la neurosis de la arqueología académica se relaciona con la expansión de los méritos propios de las llamadas "ciencias duras" y su asunción por parte de las ciencias sociales y humanidades, que se pueden resumir en el motto de "publica o perece" (publish or perish). Este tema, en el caso de la disciplina arqueológica, es lo suficientemente complejo como para que aquí no se puedan analizar todas sus aristas, si bien ha sido tratado en otros trabajos a los que remitimos (Almansa Sánchez 2011, 2013; Armada Pita 2016; Ruiz Zapatero 2016). Baste simplemente decir que, en el hipotético escenario post-COVID que se dibuja, este tipo de estrategias académicas en torno a ciertos índices de impacto profundizarán en la "hiperinflación" curricular e hipercompetitividad a la que ya se veían sometidos, sobre todo, las jóvenes investigadoras e investigadores, y provocarán una concentración de los ya escasos recursos en aquellos proyectos y líneas de investigación más acordes con una posición cientificista y positivista — podríamos decir incluso, acrítica y antihumanista (Latour y Woolgar 1986; Nussbaum 2010) — cada vez más oficial y cada vez más recompensada en la distribución de los recursos (véanse posiciones en buena parte contrapuestas en González Ruibal 2014; Kristiansen 2014). Si bien la inversión en I+D en términos absolutos había recuperado los niveles previos a la crisis de 2008 (ver figura 2), previsiblemente se producirá un doble efecto de disminución de la inversión - como ejemplo, la Junta de Andalucía ha anunciado un recorte de 135 millones de euros para la Universidad ${ }^{20}$ y de concentración sobre aquellos ámbitos más rentables (investigación aplicada, tecnología, medicina...), lo que implicará un escenario de alta competitividad por los mismos.

En prácticamente todas las noticias que se comentaron al inicio de este trabajo se reflejaba una gran preocupación por las consecuencias que la COVID-19 podía tener para las excavaciones de campo en general $\mathrm{y}$, particularmente, para aquellas que se producían en el extranjero. Evidentemente, la situación de pandemia y de crisis sanitaria ante una enfermedad de gran contagiosidad provoca una enorme incertidumbre sobre cómo operar en una disciplina en la que el contacto físico es prácticamente inevitable. Este tema tendrá necesariamente que centrar las futuras discusiones sobre las condiciones y medios en las que poder hacer arqueología de campo en el futuro, lo que sin duda tendrá que relacionarse con las condiciones laborales en términos generales - un ejemplo será la futura obligación de incorporar equipos de protección en las intervenciones. Sin embargo, existen dos peligros latentes añadidos que habrá que tener en cuenta en este sentido. Por un lado, que la competencia por

20. <https://elpais.com/sociedad/2020-05-22/la-junta-andaluzarecorta-135-millones-a-las-universidades-un-10-de-su-presupuesto. html>. 


\section{INVERSIÓN EN I+D EN TÉRMINOS ABSOLUTOS (MILLONES DE EUROS CORRIENTES) 2010-2018}

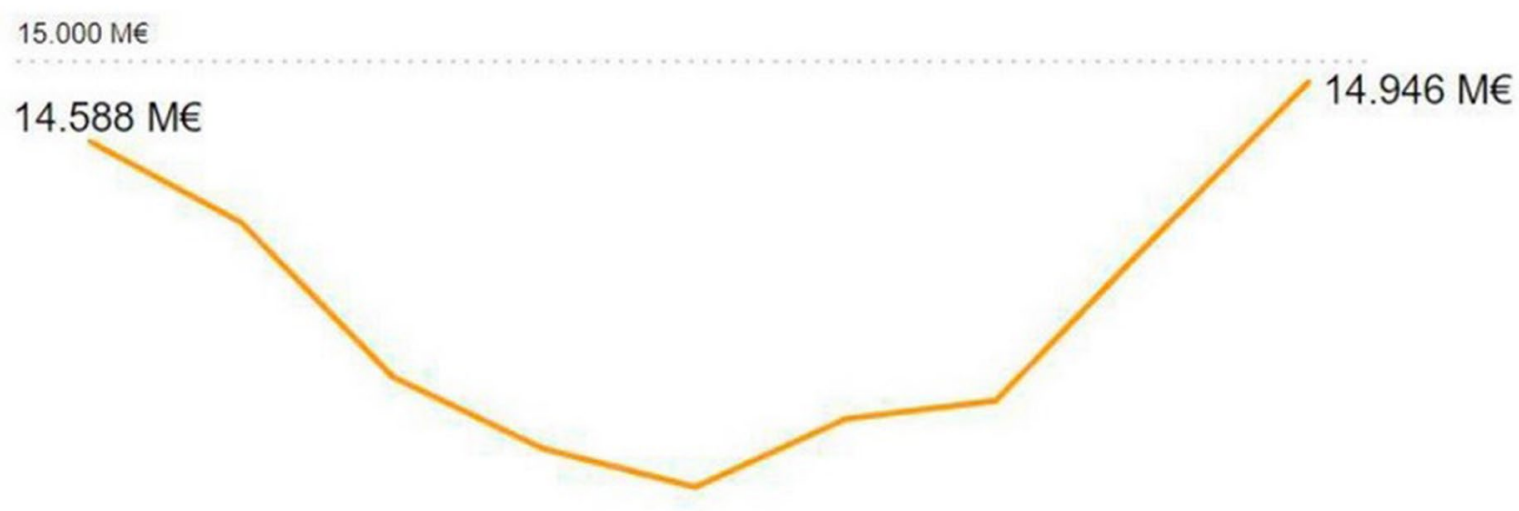

$12.000 \mathrm{M} €$

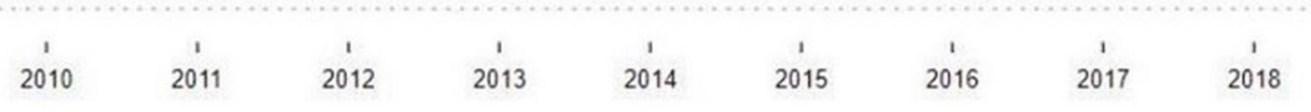

Figura 2. Inversión en I+D en términos absolutos en España según datos del Instituto Nacional de Estadística. Extraído de: $<$ https://mentesbrillantes.tv>.

los recursos, en el escenario precrisis que se está dibujando aquí, beneficiará a sectores específicos de la arqueología en perjuicio de otros, probablemente aquellos situados en una mejor posición en el campo científico de la arqueología y que más se adapte a los criterios e índices de impacto oficiales. Por otro lado, y esto se desprende de algunas de las noticias comentadas anteriormente, la instrumentalización espuria del discurso patrimonial y comunitario en la competición por esos (previsiblemente escasos) recursos (Alonso González 2017). Dicho de otra manera, el peligro de la instrumentalización de las narrativas en torno a la "defensa del patrimonio" en aras de promocionar intereses particularistas y de acumulación de capital dentro del campo científico, normalmente en detrimento de otros colectivos sociales. Esto nos lleva al último elefante en la habitación.

\section{La Arqueología y el público: "saben lo que hacen, pero aún así, lo hacen"}

En la película El tesoro (dir. Antonio Mercero, 1990), basada en la novela homónima de Miguel Delibes (Delibes 1994), un aldeano descubre con ayuda de un detector de metales un tesoro celtibérico en las tierras del pueblo colindante, llamado Gamones, y lo lleva a Madrid para recibir una recompensa. Allí le espera Jero (interpretado por José Coronado), un experto en mundo celtibérico que pronto se da cuenta de las deshonestas intenciones del aldeano:

JERO: ¿Es que se puede admitir esto? ¿Es que se puede admitir que un hombre sin ninguna experiencia arqueológica divise desde lo alto de un tractor el borde de una vasija enterrada?
LINO: Oiga, servidor no tendrá la experiencia que usted dice. Eso seguro. Pero lleva casi cuarenta años trabajando la tierra. Sabe mirarla.

Una vez superada esta confrontación y aceptada la autenticidad del tesoro, un grupo de arqueólogos, comandados por Jero, viaja hasta el pueblo para excavar el lugar donde se localizó. Pronto la comunidad local comienza a mostrar reticencias con respecto a la presencia de los arqueólogos madrileños. Como primer aviso, cuelgan un cartel en el campo que reza: "Prohibido hacer escarbaciones" (sic). Estas primeras suspicacias acaban convirtiéndose en abierta hostilidad y confrontación:

JERO: Esto es una excavación ordenada por Madrid.

PAPO: ¿Y quién es Madrid para dar órdenes en casa ajena? Lo de Madrid será para Madrid, pero lo de Gamones es de Gamones.

JERO: En Madrid está la Administración. Ella nos ha dado permiso para excavar este castro. Mire, aquí tengo una copia de ese permiso. El original se lo entregué al señor alcalde, él les puede explicar esto.

OTRO ALDEANO: Los cojones.

PAPO: ¿Y quién te ha dado ese permiso, si no es mala la pregunta?

JERO: El ministro de Cultura.

PAPO: ¿Y quién es el ministro de Cultura para meter las narices en nuestra casa? Esta mina es del pueblo, y sin una autorización del pueblo aquí no escarba ni dios.

Tanto la película como la novela pueden ser entendidas, en primera instancia, como una muestra del retraso y la ignorancia del pueblo de Gamones, 


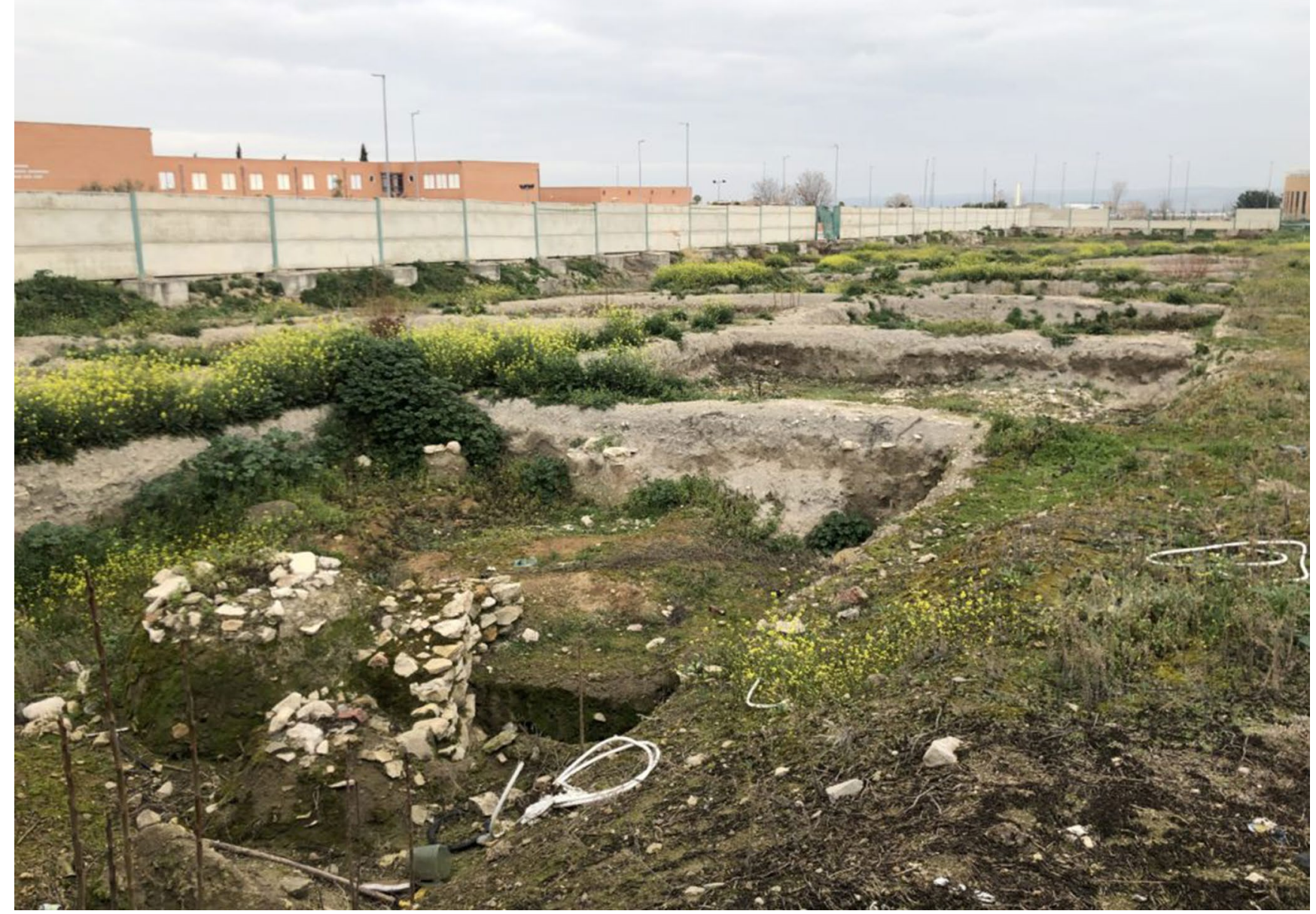

Figura 3. Yacimiento de Marroquíes Bajos (Jaén). Fuente: proyecto pubarchmed (<http://pubarchmed.tdjp.es>).

una visión muy común desde el pensamiento de clase media liberal urbana hacia las sociedades campesinas (Kearney 1996). Un ejemplo más de la concepción marxista de la ideología del "ellos no saben lo que hacen, pero lo hacen” (Marx y Engels 2014). Sin embargo, otra lectura llevaría a destacar dos de las cuestiones que han caracterizado la arqueología tradicional: por un lado, una tensa relación entre la propia disciplina y el público y/o las comunidades locales, cuyo estudio ha dado lugar a lo que se ha venido llamando "arqueología pública" (Merriman 2004; Moshenska 2017); por otro, la tradicional labor extractivista e instrumentalista de la arqueología al margen de esta relación, que ha consistido en extraer capital científico de los yacimientos y sitios arqueológicos de las comunidades $-\mathrm{O}$, en el peor de los casos, dejando estos territorios al servicio de grandes compañías extractivas-, relegando a estas últimas a un papel de espectadores pasivos (Ayán Vila y Gago 2012; Gnecco 2016). Desde este punto de vista, la historia narrada en El tesoro puede ser entendida como el enfrentamiento entre dos formas ontológicamente distintas de entender el patrimonio, la propiedad y la riqueza: por un lado, una comunidad local cuya legitimidad y autoridad se ven puestas en entredicho; por otro, los arqueólogos, autoproclamados protectores del patrimonio, la ciencia y la verdad (Ayán Vila et al. 2011).

El desarrollo de la arqueología pública en España durante estas dos primeras décadas del siglo xxI fue paradójico. Por un lado, en términos teóricos, hubo un cuestionamiento muy importante de estas labores extractivistas de la arqueología con respecto a las comunidades locales (González-Ruibal et al. 2018); pero por otro, se produjo una profundización en ciertos usos instrumentalistas de esta misma arqueología pública, sobre todo en su alianza estratégica con la arqueología comercial (ver más arriba). Así, la arqueología pública o el patrimonio y una cierta visión espuria y falsamente romántica del patrimonio y de la arqueología se convirtieron en discursos y dispositivos retóricos cuyo fin era atraer la inversión pública o privada (por ejemplo, a través del uso extendido del crowdfunding) para, en último término, aumentar el capital científico o económico de particulares externos a la propia comunidad local (Alonso González 2017). Así, los yacimientos en ruinas por falta de inversión en su mantenimiento (ver figura 3), los carteles divulgativos rotos, abandonados o los museos y centros de interpretación cerrados o las comunidades locales frustradas son tristes fósiles directores de la neurosis de la arqueología pública (Ayán Vila y Gago 2012). De 
alguna manera, la razón cínica de P. Sloterdijk fue el terreno común de una forma de hacer arqueología: "ellos saben muy bien lo que hacen, pero aun así, lo hacen" (Sloterdijk 2003).

Como bien advierte S. Žižek, este cinismo, por muy extendido y aceptado que esté, no es más que una ilusión desde la que tácitamente se acepta una fantasía de la realidad, que sigue funcionando como una ideología envolvente y fetichista: "la razón cínica, con toda su separación irónica, deja intacto el nivel fundamental de la fantasía ideológica, el nivel en el que la ideología estructura la realidad social" (Žižek 1989: 53). El antiguo aforismo marxista se modificaría entonces como "ellos saben que, en su actividad, siguen una ilusión, pero aún así, lo hacen" (Žižek 1989: 61). En la situación pre-COVID esta ilusión fue puesta en cuestión como uno de los debates más significativos dentro de la arqueología, con diversas propuestas encaminadas a revertir el tradicional papel pasivo de las comunidades locales como las del pueblo de El tesoro, al menos en lo teórico (Gnecco 2016; González-Ruibal et al. 2018; Haber 2017). No cabe duda que ya antes de la pandemia, existían formas muy interesantes de abordar esta relación entre la arqueología y el público que perseguían voluntariamente superar las ilusiones del tradicional, y no tan tradicional, extractivismo e instrumentalismo (Ayán Vila et al. 2011). ${ }^{21}$

La COVID-19 y sus previsibles consecuencias (recorte en gasto público, desregulación del mercado inmobiliario, desprotección del patrimonio, etc.) puede generar una situación de agudización de la neurosis de la arqueología, y en esta situación de huida hacia adelante, en aras de la supervivencia del sector, profundizar en las políticas extractivistas y de instrumentalización de las comunidades locales, en detrimento tanto de estas como del propio patrimonio. Una situación muy similar a lo que supuso la crisis del 2008 en términos teóricos y prácticos (Hernando 2012b), pero ahora con un sector mucho más débil y mucho menos organizado. Una vuelta a la razón cínica bajo la que sabemos perfectamente lo que estamos haciendo y, aún así, lo seguiremos haciendo.

\section{La arqueología post-COVID: de la guerra de trincheras a la guerra de posiciones}

Ya antes de la pandemia, y con relación al auge de la extrema derecha en toda Europa, había muchas voces que alertaban de las similitudes que se daban entre la situación actual y la de entreguerras mundiales (Delle Donne y Jerez 2019; Eatwell y Goodwin 2018). Como se comentaba al inicio, no son pocas las personas que advierten de una profundización de políticas y relaciones de tipo autoritario con el objetivo de mantener las relaciones de producción capitalistas. Al fin y al cabo, si algo han demostrado el capitalismo y el neoliberalismo, es una extremada

21. Por ejemplo, muchas de las propuestas presentadas a los congresos internacionales sobre Educación y Socialización del Patrimonio en el Medio Rural (SOPA). capacidad de salir indemne de las crisis (Mirowski 2014). El objetivo de este trabajo era reflexionar sobre el impacto de la COVID-19 en la disciplina arqueológica y sobre la conflictiva situación previa sobre la que la pandemia venía a impactar. No sería lícito terminarlo sin, al menos, una reflexión similar en torno a las posibilidades y perspectivas de futuro y, para ello, tal vez sería bueno retomar algunas de las ideas surgidas en aquella situación de entreguerras, caracterizada también por una situación de crisis y de retroceso de los avances emancipadores que provocaron la reacción de diversos intelectuales. En este caso, los conceptos de "revolución pasiva", "guerra de trincheras" y "guerra de movimiento" de A. Gramsci pueden ser extremadamente útiles para el propósito de esta reflexión final (Gramsci 2015).

De todas las posibles consecuencias para la arqueología derivadas de la pandemia de la COVID-19 presentadas a lo largo del texto, algunas serían más directas, caso del previsible recorte de financiación pública y privada, la precarización del trabajo arqueológico en todas sus ramas o la destrucción en el corto plazo de los medios de producción (empresas y autónomos). Otras, en cambio, serían más indirectas, como la hipercompetitividad por los escasos puestos de trabajo, la hiperinflación de los marcos curriculares basada en determinados índices de impacto o la concentración del capital científico dentro del campo disciplinario. Un terreno general de profundización de la neurosis previa de la arqueología que se convierte en un caldo de cultivo para una revolución pasiva, esto es, una aparente modificación de las condiciones coyunturales que, en esencia, deja sin tocar los elementos estructurales en la base de la crisis. Una reacción típicamente neurótica del "sálvese quien pueda", sostenida por un creciente individualismo que no solo ha sido característico de la arqueología, sino de la sociedad contemporánea en general (Han 2017; Hernando 2012a), con la paradójica, y trágica, conclusión lampedusiana de que todo cambie para que nada cambie. En palabras del economista Juan Torres López:

Es decir, el coronavirus (la crisis sanitaria que provoca) es realmente peligroso no sólo por lo que supone en sí mismo sino porque aumenta mucho la degradación del sistema en su conjunto, en mucha mayor proporción de la que correspondería a su aislada naturaleza de epidemia sanitaria. A mi juicio, la extraordinaria gravedad del coronavirus no es el daño que produciría una epidemia si se pudiera contemplar aisladamente, sino la aceleración del efecto degradante o destructor de los demás fallos que estaban más o menos contenidos hasta ahora (Torres López 2020: 30).

Este texto pretende ser una llamada de atención sobre este punto y una propuesta de confrontación ante una situación que, como todo shock, puede funcionar como una forma de profundizar en los problemas estructurales o de confrontarlos y superarlos (Klein 2008), dependiendo de la capacidad de reacción y de análisis de la coyuntura: "It is only now, when I have to avoid many of those who are close to me, that I fully experience their presence, their importance to me" (Žižek 2020: 3). Y en este reconocimiento de la situación, se siguen necesa- 
riamente las actitudes reactivas. La encuesta y las propuestas de la Plataforma Estatal de Profesionales de la Arqueología de mayo de 2020 representan una reacción necesaria dentro de la política de guerra de trincheras que tocará plantear en el corto plazo. En este sentido, se puede abogar por un cierto consenso en torno a coordenadas como la defensa de la inversión pública en todas sus vertientes (patrimonio, universidad pública, investigación y desarrollo...), la protección del patrimonio ante la desregulación del sector inmobiliario y la consiguiente desprotección de los yacimientos y los paisajes, o la mantención y mejora de las condiciones laborales ante una eventual precarización. Menos clara, sin embargo, puede ser la cuestión de la defensa de lo público frente a lo privado, dadas las características de clase del sector y de los intereses derivados del mismo (Díaz del Río 2000). Los embates del sector privado no se han hecho esperar, y, como vimos, ya se están haciendo movimientos para favorecer los intereses de las empresas privadas en la universidad (ver más arriba), bajo una retórica de progreso y modernización que hasta el propio ministerio está utilizando. No hay duda de que este tipo de cuestiones, en la guerra de trincheras, serán frentes esenciales de debate y acción.

Sin embargo, es fundamental tener puesta la vista en la futura guerra de maniobras una vez se asiente la "nueva normalidad". El debate sobre el papel que la arqueología puede, quiere, y debe jugar en las sociedades contemporáneas no es, ni mucho menos, nuevo, pero la COVID-19 nos pone ante una situación de urgencia por reorganizar los códigos de valores, la institucionalización y la relación de la disciplina con la sociedad. Para esto es necesario dilucidar primero qué papel se puede, quiere y debe jugar en el contexto capitalista actual y, en segundo lugar, reflexionar sobre cómo posicionar a la arqueología en otras coordenadas alternativas, lo que implica de alguna manera hacerla socialmente necesaria y políticamente comprometida (González-Ruibal et al. 2018; McGuire 2008). En el medio plazo, tres considero que serían las prioridades. En primer lugar, generar colectivo y diversificar las herramientas de articulación del mismo en todos los ámbitos posibles, lo que implicará (quizá lo más complicado) superar el individualismo y egocentrismo característicos de la disciplina en todas sus vertientes. En segundo lugar, y en consonancia con lo anterior, combatir y superar el clientelismo que vertebra todos los ámbitos de la arqueología en aras de un sistema más meritocrático bajo parámetros que no perjudiquen a ningún colectivo —con especial referencia a las mujeres en el caso del sistema español (Hernando 2012a; Sánchez Romero 2005). La mejor vía para lograr esto es la conjunción de, en primer lugar y más importante, una regulación más adecuada e independiente para el acceso a contratos y puestos de trabajo, con sistemas de evaluación eficaces, y, en segundo lugar, el desarrollo de una ética colectiva que rechace y supere los abusos de poder. En tercer lugar, reforzar y profundizar en todas las herramientas de gestión estratégica (desde los Planes de Ordenación Urbana hasta los Planes Estatales) bajo criterios consensuados por todos los agentes implicados (y no solo desde los cargos políticos) y velar por su cumplimiento con una financiación estable y adecuada.

En el largo plazo, la superación de la neurosis intrínseca a la disciplina pasa, quizá, por desarrollar un sistema alternativo de méritos e índices de impacto que permitan reorientar los sistemas de reproducción del campo científico; o por reorientar las prioridades de la arqueología reduciendo los ritmos de excavación, de destrucción del patrimonio y del extractivismo para hacer una reflexión más profunda o digerir de forma crítica, comprensiva y financiada públicamente todos los materiales que acumulan polvo en los museos; o reorientar la inversión pública en investigación básica e intervenciones menos destructivas con el medio ambiente y el patrimonio; o por introducir y dialogar con esas comunidades locales que, como en El tesoro, se han sentido fuertemente despreciadas por la disciplina. Al fin y al cabo, asumir el estado de neurosis, reconocer sus causas y querer superarla es el primer paso para curarse, para saber lo que hacemos $\mathrm{y}$, además, querer hacerlo con ganas.

\section{Carlos Tejerizo-García Universidad del País Vasco Facultad de Letras, \\ Paseo de la Universidad, 5, 01006 , Vitoria-Gasteiz (Álava)}

Data de recepció: 5/06/2020 Data d'acceptació: 2/07/2020 
Alegre, L., Moreno, V. (2009). Bolonia no existe. La destrucción de la Universidad Europea. Sediciones. Madrid.

Almansa Sánchez, J. (2011). El futuro de la Arqueología en España. JAS Arqueología. Madrid.

Almansa Sánchez, J. (ed.) (2013). Arqueología pública en España. JAS Arqueología. Madrid.

Alonso GonzÁlez, P. (2017). El antipatrimonio: fetichismo y dominación en Maragatería. CSIC. Madrid.

Armada Pita, X. L. (2016). Explorando el panorama actual de las publicaciones periódicas de arqueología. Revista d'Arqueologia de Ponent, 26: 295-310.

Ayán Vila, X., Gago, M. (2012). Herdeiros pola forza. Patrimonio cultural, poder e sociedade na Galicia do Século XXI. 2.0. Editora. Ames.

Ayán Vila, X., González Veiga, M., Rodríguez Martínez, R. M. (2011). Más allá de la Arqueología Pública: arqueología, democracia y comunidad en el yacimiento multivocal de A Lanzada. Treballs d'Arqueologia, 18: 63-98.

Barreiro Martínez, D. (2013). Arqueológicas. Hacia una arqueología aplicada. Bellaterra. Barcelona.

Bourdieu, P. (1984). Homo academicus. Minuit. París.

Bourdieu, P. (2003). El oficio de científico: ciencia de la ciencia y reflexividad. Anagrama. Barcelona.

Capella, J.-R. (2009). La crisis universitaria y Bolonia. El Viejo Topo, 252: 9-15.

Castillo, J. J., Moré, P. (2018). Universidad precaria, universidad sin futuro. Fuhem. Madrid.

Cномкку, N. (1969). La responsabilidad de los intelectuales. Ariel. Barcelona.

Delibes, M. (1994). El tesoro. Círculo de Lectores. Madrid.

Delle Donne, F., Jerez, A. (2019). Epidemia ultra. Publicación independiente. Berlín.

Derickson, K. (2016). Resilience is not enough. City, 20, 1: 161-166.

Díaz-Andreu, M. (2002). Historia de la Arqueología. Estudios. Ediciones Clásicas. Madrid.

Díaz DEL Río, P. (2000). Arqueología Comercial y estructura de clase. CAPA, 12: 7-18.

Eatwell, R., Goodwin, M. (2018). National populism: the revolt against liberal democracy. Penguin. Londres.
Fernández Liria, C., Serrano García, C. (2009). El Plan Bolonia. Catarata. Madrid.

Gnecco, C. (2016). Antidecálogo. Diez ensayos (casi) arqueológicos. Editorial Universidad del Cauca/JAS Arqueología/Ediciones del Signo. Popayán.

González-Ruibal, A. (2012a). Cada vez más islas. Arkeogazte, 2: 17-19.

GonZÁlez-Ruibal, A. (2012b). El desastre académico de la arqueología. En: J. Almansa SÁnchez (ed.). El futuro de la Arqueología de España. JAS Arqueología. Madrid: 99-104.

González-Ruibal, A., Alonso González, P., Criado Boado, F. (2018). Against reactionary populism: towards new public archaeology. Antiquity, 92, 362: 507-515.

GonzÁlez Álvarez, D. (2013). Las "excavaciones de verano": forjando superarqueólogos fácilmente precarizables. Arkeogazte, 3: 201-219.

GonzÁlez Ruibal, A. (2014). Archaeological revolution(s). Current Swedish Archaeology, 22: 41-45.

Gracia Alonso, F. (2009). La arqueología del primer franquismo (1939-1956). Bellaterra. Barcelona.

Gramsci, A. (2015). Antología. Selección, traducción y notas de Manuel Sacristán. Akal. Madrid.

Haber, A. F. (2017). Al otro lado del vestigio. Políticas del conocimiento y arqueología indisciplinada. Editorial Universidad del Cauca/JAS Arqueología/Ediciones del Signo. Popayán/Madrid/Buenos Aires.

HaN, B.-C. (2017). La sociedad del cansancio. Herder. Barcelona.

Hernández Díaz, J. M. (1997). La Universidad en España, del Antiguo Régimen a la LRU (1983). Hitos y cuestiones destacadas. Aula, 9: 19-44.

Hernando, A. (2012a). La fantasía de la individualidad: sobre la construcción sociohistórica del sujeto moderno. Katz. Madrid.

Hernando, A. (2012b). Teoría arqueológica y crisis social. Complutum, 23, 2: 127-145.

Hernando Álvarez, C., Tejerizo García, C. (2011). La Arqueología y la Academia: del siglo xIX al "Plan Bolonia”. Revista Arkeogazte, 1: 50-66.

Houben, H. (2012). La crisis de 30 años. ¿El fin del capitalismo? Fundación Jaime Lago. Oviedo.

Jessop, B. (2016). The State. Past, Present, Future. Polity Press. Cambridge. 
KEARNEY, M. (1996). Reconceptualizing the peasantry. Anthropology in Global Perspective. Westview Press. Boulder.

KLEIN, N. (2008). The shock doctrine: the rise of disaster capitalism. Picador-Macmillan. Nueva York.

Kristiansen, K. (2014). Towards a new paradigm? The third science revolution and its possible consequences in Archaeology. Current Swedish Archaeology, 22: 11-34.

Lacalle, D. (2006). La clase obrera en España: continuidades, transformaciones, cambios. El Viejo Topo. Barcelona.

Latour, B., Woolgar, S. (1986). Laboratory life. The construction of scientific facts. Princeton University Press. Nueva Jersey.

Marcuse, H. (2010). Eros y civilización. Ariel. Barcelona.

Marín SuÁrez, C., Parga-Dans, E. (2015). Arqueologia de gestão em Madri: presos pelo modelo de especulação capitalista do território. Revista de Arqueología, 28, 2: $118-138$

Marx, K., Engels, F. (2014). La ideología alemana. Akal. Madrid.

McGuire, R. H. (2008). Archaeology as political action. University of California Press. Los Ángeles.

Merriman, N. (2004). Public archaeology. Routledge. Londres.

Ministerio de Ciencia, I. y U. (2019). Datos y cifras del sistema universitario español. Ministerio de Ciencia, Innovación y Universidades. Madrid.

Mirowski, P. (2014). Nunca dejes que una crisis te gane la partida. ¿Cómo ha conseguido el neoliberalismo, responsable de la crisis, salir indemne de la misma? Ediciones Deusto. Barcelona.

Moshenska, G. (2017). Key concept in Public Archaeology. UCL Press. Londres.

Napolitano, G. (2013). Categorías clínicas y teoría psicoanalítica: puntuaciones en la obra de Freud. En: G. Napolitano (ed.). El campo de la neurosis en la obra de Freud. EDULP. La Plata: 18-58.

Novakovic, P., Hornak, M., Pia Guermandi, M., Stäuble, H., Depaepe, P., Demoule, J.-P. (2016). Recent developments in Preventive Archaeology in Europe. Ljubljana University Press. Ljubljana.

Nussbaum, M. C. (2010). Sin fines de lucro. Katz. Buenos Aires.

PARga-Dans, E. (2009). El mercado del patrimonio: nacimiento, estructura y desarrollo de las empresas que gestionan el patrimonio arqueológico. $C A P A, 21$.

Parga-Dans, E. (2010). Commercial archaeology in Spain: its growth, development, and the impact of the global economic crisis. En: N. Schlanger, K. Aitchison (eds.). Archaeology and the global economic crisis. Multiple impacts, possible solutions. Culture Lab Editions. Tervuren: 45-54.

Parga-Dans, E., Castro Martínez, E., Fernández de Lucio, I. (2012). La arqueología comercial en España: ¿un sistema sectorial de innovación? Cuadernos de Gestión, 12: 139-156.

Pepa, PLATAFORMA ESTATAL DE PROFESIONALES DE LA ARQUEOLOGÍA (2020). Informe del impacto económico de la COVID-19 en la Arqueología profesional a nivel estatal. Madrid.

Querol, M. Á. (1998). La Arqueología en las Universidades españolas. Boletín del Instituto Andaluz del Patrimonio Histórico, 22: 15-18.

Querol, M. Á. (2001). La formación y la profesión del arqueólogo. La formación arqueológica universitaria: un futuro por el que luchar. PHBoletín, 37: 32-34.

Querol, M. Á. (2005). La génesis del título universitario de arqueología: desde mi ángulo. Complutum, 16: 213-219.

Querol, M. Á. (2010). Manual de gestión del patrimonio cultural. Akal. Madrid.

Ruiz Zapatero, G. (2005). ¿Por qué necesitamos una titulación de Arqueología en el siglo XXI? Complutum, 16: 255-269.

Ruiz Zapatero, G. (2009). ¿Qué arqueología enseñar en la universidad del siglo xxi? Complutum, 20, 2: 225-254.

Ruiz Zapatero, G. (2016). Presente y futuro de la Arqueología en España. Luces, sombras y desafíos. En: D. Vaquerizo Gil, A. B. Ruiz, M. Delgado (eds.). Rescate. Del registro estratigráfico a la sociedad del conocimiento: el patrimonio arqueológico como agente de desarrollo sostenible. Editorial Universidad de Córdoba. Córdoba: 53-75.

SÁnchez Romero, M. (2005). Arqueología y género. Universidad de Granada. Granada.

Scotт, J. C. (1985). Weapons of the Weak. Everyday Forms of Peasant Resistance. Yale University Press. New Haven.

Serrano García, C. (2009). El fin de la Universidad Pública. En: L. Alegre, V. Moreno (eds.). Bolonia no existe. La destrucción de la Universidad Europea. Sediciones. Madrid: 64-78.

SloterdiJK, P. (2003). Crítica de la razón cínica. Siruela. Madrid.

Tejerizo García, C., Hernando Álvarez, C. (2012). Arqueología en su contexto: formación y profesionalización tras Bolonia. En: Actas de las IV Jornadas de Jóvenes en Investigación Arqueológica. Faro: 317-324. 
Torres López, J. (2020). Coronavirus y economía. Recopilación de artículos sobre los efectos económicos de la pandemia del coronavirus.

Vigil-Escalera, A. (2011). El pequeño mundo en ruinas de la Arqueología contractual española. Revista Arkeogazte, 1: 17-20.

VV.AA. (2020). Sopa de Wuhan. Pensamiento contemporáneo en tiempos de pandemias. ASPO.
ŽIžEK, S. (1989). The Sublime Object of Ideology. Verso. Londres.

ŽIžEK, S. (2016). Contragolpe absoluto. Para una refundación del materialismo dialéctico. Akal. Madrid.

ŽıžEK, S. (2020). Pandemic. Polity Press. Nueva York. 